\title{
Synthesis of zirconium titanate with an ordered M-fergusonite (beta) structure
}

\author{
Ulrike Troitzsch*, Andrew G. Christy, David J. Ellis \\ Department of Earth and Marine Sciences, Australian National University, Canberra, ACT 0200, Australia \\ Received 5 April 2007; received in revised form 13 August 2007; accepted 29 August 2007 \\ Available online 4 September 2007
}

\begin{abstract}
We report a new zirconium titanate compound $(\mathrm{Zr}, \mathrm{Ti}) \mathrm{O}_{2}$ with $27.5-35 \mathrm{~mol} \%$ titania $\left(\mathrm{TiO}_{2}\right)$ formed from the oxides at $35-38 \mathrm{kbar}$, 1400-1500 ${ }^{\circ} \mathrm{C}$. Crystal structure investigations at atmospheric conditions with powder X-ray diffraction (XRD) and transmission electron

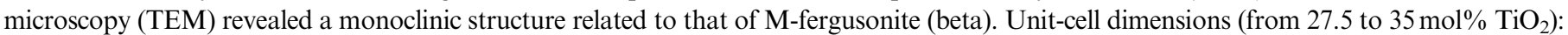
$a=7.267(20)-7.340(2) \AA, \quad b=10.435(3)-10.429(1) \AA, c=5.023(11)-5.040(1) \AA, \quad \beta=136.45(12)-137.55(1)^{\circ}, \quad V=262.44(92)-260.40(12) \AA^{3}$, $Z=4$. Rietveld refinement $\left(R_{\mathrm{F}}=1.55\right)$ of a sample with $32.8 \mathrm{~mol} \% \mathrm{TiO}_{2}$ indicates that site $A$ is 8 -fold coordinated, mostly occupied by $\mathrm{Zr}$, while site $B$ has 6 -fold average coordination, occupied by Ti and $\mathrm{Zr}$. Site $B$ is at least partly ordered, as indicated by superstructure reflections 001 and -201 detected with TEM, reducing the space group from $C 2 / c$ to $C 2$. Pronounced streaking of selected diffraction spots is linked to the boundaries of lamellar domains in twin orientation, with twin planes either (200) or (20-2). Adjacent lamellae differ slightly in composition, causing subtle asymmetry of the twin diffraction patterns.
\end{abstract}

(C) 2007 Elsevier Inc. All rights reserved.

Keywords: Zirconium titanate; Crystal structure; Fergusonite; Ordering; Twinning

\section{Introduction}

The zirconia $\left(\mathrm{ZrO}_{2}\right)$-titania $\left(\mathrm{TiO}_{2}\right)$ system has been extensively studied, since the limited number of compounds in this system shows numerous interesting and useful properties. These compounds include:

(i) the polymorphs of zirconia $\left(\mathrm{ZrO}_{2}\right)$, known for chemical inertness, toughness, ionic conductivity, and interesting electrical properties, and used as a refractory, structural ceramic, for high-temperature solidelectrodes, and optical ceramics [1];

(ii) zirconium titanate $\left(\mathrm{ZrTiO}_{4}\right)$ with scrutinyite $\left(\alpha-\mathrm{PbO}_{2}\right)$ structure, used for example as temperature-stable dielectric material for ceramic capacitors, as stable oscillator at microwave frequencies in satellite communication, and investigated for its potential use as pigment [2-5] and

(iii) the polymorphs of $\mathrm{TiO}_{2}$, used as pigments [6], abrasives, and dielectric ceramics.

\footnotetext{
*Corresponding author. Fax: +6126125 5544.

E-mail address: ulrike@ems.anu.edu.au (U. Troitzsch).
}

Due to their electrical properties, most of these compounds are objects of thin-film and nano-laminate studies [7-10].

These compounds form limited solid solutions along the binary $\mathrm{ZrO}_{2}-\mathrm{TiO}_{2}$ join, whereby the extent of solution varies with synthesis conditions. Since the physical properties of the solid solutions change with chemical composition and crystal structure (e.g. [11,3]) research focused on the interplay between structure and composition, as presented in this study, is fundamental in the search for improved ceramics or the discovery of new compounds in this system (e.g. [12]).

The composition of $(\mathrm{Zr}, \mathrm{Ti}) \mathrm{O}_{2}$ solid solutions synthesized by sintering at ambient pressure is limited by the phase boundaries in the equilibrium $\mathrm{ZrO}_{2}-\mathrm{TiO}_{2}$ phase diagram to $\leqslant 19 \mathrm{~mol} \%\left(\mathrm{ZrO}_{2}\right), 42-58 \mathrm{~mol}_{0}\left(\mathrm{ZrTiO}_{4}\right)$ and $\geqslant 82 \mathrm{~mol} \%$ $\mathrm{TiO}_{2}$ [13,14]. Compositions of metastable compounds outside this range can be achieved with low-temperature processes such as ball-milling [15], annealing of sol-gel precipitates [16], or thin-film sputtering [8]. While these synthesis methods are known to produce a wide variety of metastable compounds with non-equilibrium compositions 
Table 1

Experimental details

\begin{tabular}{|c|c|c|c|c|c|c|c|}
\hline Sample & $\begin{array}{l}\text { Starting mix } \\
\left(\mathrm{mol}^{\circ} \mathrm{TiO}_{2}\right)\end{array}$ & $T\left({ }^{\circ} \mathrm{C}\right)$ & $P$ (kbar) & $t(\mathrm{~h})$ & $\begin{array}{l}\text { Cooling rate } \\
(\% / s)\end{array}$ & $\begin{array}{l}\text { Product } \\
\text { phases }^{\mathrm{a}}\end{array}$ & $\begin{array}{l}Z_{\mathrm{F}} \text { composition } \\
\left(\mathrm{mol}^{\circ} \mathrm{TiO}_{2}\right)\end{array}$ \\
\hline G-549 & 25 & 1400 & 28 & 20 & $>140$ & $Z_{\mathrm{M}} Z_{\mathrm{T}} Z_{\mathrm{F}} Z \mathrm{~T}$ & $27.5(9)$ \\
\hline G-655 & 30 & 1400 & 38 & 9 & $>140$ & $Z_{\mathrm{F}}$ & 29.4(9) \\
\hline G-660 & 32 & 1400 & 38 & 9 & $>140$ & $Z_{\mathrm{F}}$ & $32.2(1)$ \\
\hline G-661 & 32 & 1400 & 38 & 9 & Slow $^{\text {b }}$ & $Z_{\mathrm{F}}$ & $32.8(3)$ \\
\hline G-534 & 40 & 1400 & 38 & 24 & $>140$ & $Z_{\mathrm{F}} \mathrm{ZT}$ & $34.9(5)$ \\
\hline
\end{tabular}

${ }^{\mathrm{a}}$ Product phases are $(\mathrm{Zr}, \mathrm{Ti}) \mathrm{O}_{2}$ solid solutions with the structure of monoclinic zirconia $\left(Z_{\mathrm{M}}\right)$, tetragonal zirconia $Z_{3} \mathrm{TiO}_{8}\left(Z_{\mathrm{T}}\right)[12], \mathrm{M}_{-}$fergusonite $\left(Z_{\mathrm{F}}\right)$ and scrutinyite $(\mathrm{ZT})$.

${ }^{\mathrm{b}} 5^{\circ} / \mathrm{min}$ (from 1400 to $1150{ }^{\circ} \mathrm{C}$ ) and $35^{\circ} / \mathrm{min}$ (from 1150 to $800^{\circ} \mathrm{C}$ ).

and structure types, the resulting materials are typically poorly crystallized, very fine-grained, and not necessarily suited for detailed structural investigation beyond unit-cell determination [17]. In contrast, recent equilibrium syntheses of $(\mathrm{Zr}, \mathrm{Ti}) \mathrm{O}_{2}$ solid solutions at high pressures and temperatures in our experimental laboratory, and their subsequent quenching to ambient conditions, have resulted in reasonably well-crystallized samples, while extending the limiting compositions of $\mathrm{ZrO}_{2}$ and $\mathrm{ZrTiO}_{4}$ to 26 and $67 \mathrm{~mol}_{\%} \mathrm{TiO}_{2}$, respectively [18]. High-pressure syntheses have also led to the recent discovery of the tetragonal compound $\mathrm{Zr}_{3} \mathrm{TiO}_{8}$, structurally similar to tetragonal $\mathrm{ZrO}_{2}$, but with a double-sized, scheelite-like unit cell due to cation ordering [12].

The present study explores the compositional range between $\mathrm{Zr}_{3} \mathrm{TiO}_{8}$ and $\mathrm{ZrTiO}_{4}$ solid solution with additional highpressure synthesis experiments, and demonstrates the stabilization of a previously unknown compound between 27.5 and $35 \mathrm{~mol} \% \mathrm{TiO}_{2}$ with an ordered $\mathrm{M}$-fergusonite structure.

\section{Experimental procedures}

\subsection{Synthesis}

All samples were reacted from the oxides at high pressures and temperatures (Table 1), using a pistoncylinder apparatus at the Department of Earth and Marine Sciences, ANU, with experimental procedures and components as described in Troitzsch and Ellis [18].

Starting mixes were prepared from the oxides $\mathrm{ZrO}_{2}$ (samples G-655, 660, 661: Aldrich; G-534, 549: SPEX) and $\mathrm{TiO}_{2}$ (samples G-655, 660, 661: Aldrich; G-534, 549: Degussa), which were dried separately at $1100{ }^{\circ} \mathrm{C}$ for $1 \mathrm{~h}$ to drive off any adsorbed or structural water that could affect the weighing process. About $5 \mathrm{wt} \%$ of a flux, $\mathrm{CuO}$ (Aldrich) or ammonium carbonate mixture (UNIVAR) was added to all mixes except G-549 to speed up equilibration. ${ }^{1}$ The flux disappears entirely during the experiments and does not affect the subsequent structure

\footnotetext{
${ }^{1}$ Sample G-549 belongs to an older sequence of experiments run without flux, but was included into this study as the results complement the present data set.
}

refinements [19]. The oxides were mixed in various proportions (Table 1), hand-ground in acetone in an agate mortar, and dried.

These starting mix powders were pressed into $2-\mathrm{mm} \mathrm{Pt}$ capsules that were then welded shut. These were surrounded by $\mathrm{Fe}_{2} \mathrm{O}_{3}$ inside a second, larger Pt capsule, to prevent any reduction of $\mathrm{Ti}^{4+}$ to $\mathrm{Ti}^{3+}$ in the sample, as commonly seen in unbuffered piston cylinder runs [20]. After first reaching the desired pressure, the temperature was increased to target temperature at a rate of $120^{\circ} \mathrm{C} / \mathrm{min}$. At the end of the experiment, all samples, except for G-661, were quenched as fast as possible by turning off the power, equivalent to a cooling rate of about $140{ }^{\circ} \mathrm{C} / \mathrm{s}$. Sample G661 was cooled more slowly, as detailed in Table 1, to investigate any effect of cooling rate on the run products. Each experiment resulted in one cylindrical sample of about $1.5 \mathrm{~mm}$ diameter and $2 \mathrm{~mm}$ length.

\section{2. $X$-ray diffraction $(X R D)$}

All samples were analysed with a Siemens D501 diffractometer, equipped with a curved graphite monochromator and a scintillation detector, using $\mathrm{Cu} K \alpha$ radiation. The samples were ground in acetone, placed on a low-background quartz sample holder, and scanned between 5 and $90^{\circ} 2 \theta$, at a step-width of $0.02^{\circ}$ and scan speed of $0.5^{\circ} / \mathrm{min}$. Unit-cell dimensions of all samples, and crystal structure data of sample G-661 were refined with the Rietveld method using the program RIETAN-2000 [21] with a pseudo-Voigt profile function. The starting parameters were those of M-fergusonite [22]. All product phases shown in Table 1 were included in the profile fitting. Refined non-atomic parameters include one for specimen displacement, 10 background parameters, scale factors, up to 5 peak shape parameters per phase, and unitcell parameters. Total occupation factors of all sites were set to 1 . Site $A$ was initially fully occupied with $\mathrm{Zr}$, and the site $B$ with $\mathrm{Ti}$ and $\mathrm{Zr}$ in proportions corresponding to the compositions independently determined with scanning electron microscope (SEM). $\mathrm{Zr}$ and $\mathrm{Ti}$ occupancies were varied to improve the fit during the refinement of sample G-661. One common thermal parameter $B$ was used for oxygen positions $\mathrm{O} 1$ and $\mathrm{O} 2$. 


\subsection{Scanning electron microscopy (SEM)}

Quantitative analyses were obtained with a JEOL JSM6400 SEM with attached $\mathrm{Si}(\mathrm{Li})$ detector, Link ISIS EDS, at $15 \mathrm{kV}$ and $1 \mathrm{nA}$. Analyses were quantified using ZAF correction. Synthetic, homogeneous zirconolite was used as standard for $\mathrm{Zr}$ and $\mathrm{Ti}$. The analyses have an estimated error of $0.5 \mathrm{wt} \%$ for each oxide.

\subsection{Transmission electron microscopy (TEM)}

The monophase samples G-655, G-660 and G-661 were investigated with TEM. Imaging and diffraction was carried out at $300 \mathrm{kV}$ using a Philips EM 430 TEM (G655, 660), and a Philips CM300T (G-661) with a $\mathrm{LaB}_{6}$ filament, and a Gatan 794 multi-scan CCD camera. Samples were prepared by the dispersion of finely ground material onto a holey carbon-coated copper grid.

\section{Results and discussion}

\subsection{Run products}

Samples G-655, G-660 and G-661 reacted completely to $\mathrm{ZrTiO}_{4}$ with a narrow compositional range (Table 1, Fig. 1a). The XRD patterns of these samples could not be assigned or fitted to any of the known $\mathrm{ZrO}_{2}$ or $\mathrm{ZrTiO}_{4}$ structures (Fig. 2, middle).

The most $\mathrm{TiO}_{2}$-rich sample (G-534) also equilibrated well, but to a two-phase mixture, in which each phase is of a distinct composition (34.9 and $65 \mathrm{~mol}^{\%} \mathrm{TiO}_{2}$ ) (Fig. 1b). The diffraction pattern indicates the presence of $\mathrm{ZrTiO}_{4}$ with scrutinyite $\left[\alpha-\mathrm{PbO}_{2}\right]$ structure, i.e. $(\mathrm{Zr}, \mathrm{Ti}) \mathrm{O}_{2}$ solid solution with $65 \mathrm{~mol} \% \quad \mathrm{TiO}_{2}$, and the unidentified phase above (Fig. 2, bottom). This sample evidently equilibrated within a two-phase field, and represents the maximum $\mathrm{TiO}_{2}$-content of the unidentified phase that is achievable with the experimental conditions of this study $\left(34.9 \mathrm{~mol}_{0} \mathrm{\textrm {TiO } _ { 2 }}\right.$ ).

The only sample that did not contain flux in the starting mix (G-549) did not equilibrate completely (see footnote 1). While only two phases with compositions 17-28 and $61 \mathrm{~mol} \% \mathrm{TiO}_{2}$ could be distinguished with SEM (not shown), four different phases were identified with XRD (Fig. 2, top). These are: monoclinic $\mathrm{ZrO}_{2}$, tetragonal $\mathrm{Zr}_{3} \mathrm{TiO}_{8}$, a trace of $(\mathrm{Zr}, \mathrm{Ti}) \mathrm{O}_{2}$ with the scrutinyite structure, and the new phase. The spread of compositions encountered with SEM can be assigned to the previously known phases as follows. The scrutinyite compound contains $65 \mathrm{~mol}_{0} \mathrm{TiO}_{2}$ [23]; $\mathrm{Zr}_{3} \mathrm{TiO}_{8}$ has about $25 \mathrm{~mol} \% \mathrm{TiO}_{2}$ [12]; monoclinic $\mathrm{ZrO}_{2}$ can be expected to have compositions $\leqslant 26 \mathrm{~mol} \% \mathrm{TiO}_{2}$ [12]. Hence, compositions of about $27-28 \mathrm{~mol}^{\%} \mathrm{TiO}_{2}$ in this sample must belong to the new, unidentified phase.

Fig. 3 shows the very strong control of composition on the crystal structure of $\mathrm{ZrTiO}_{4}$ compounds over the narrow range of $25-35 \mathrm{~mol} \% \mathrm{TiO}_{2}$. The uppermost scan [from 12]
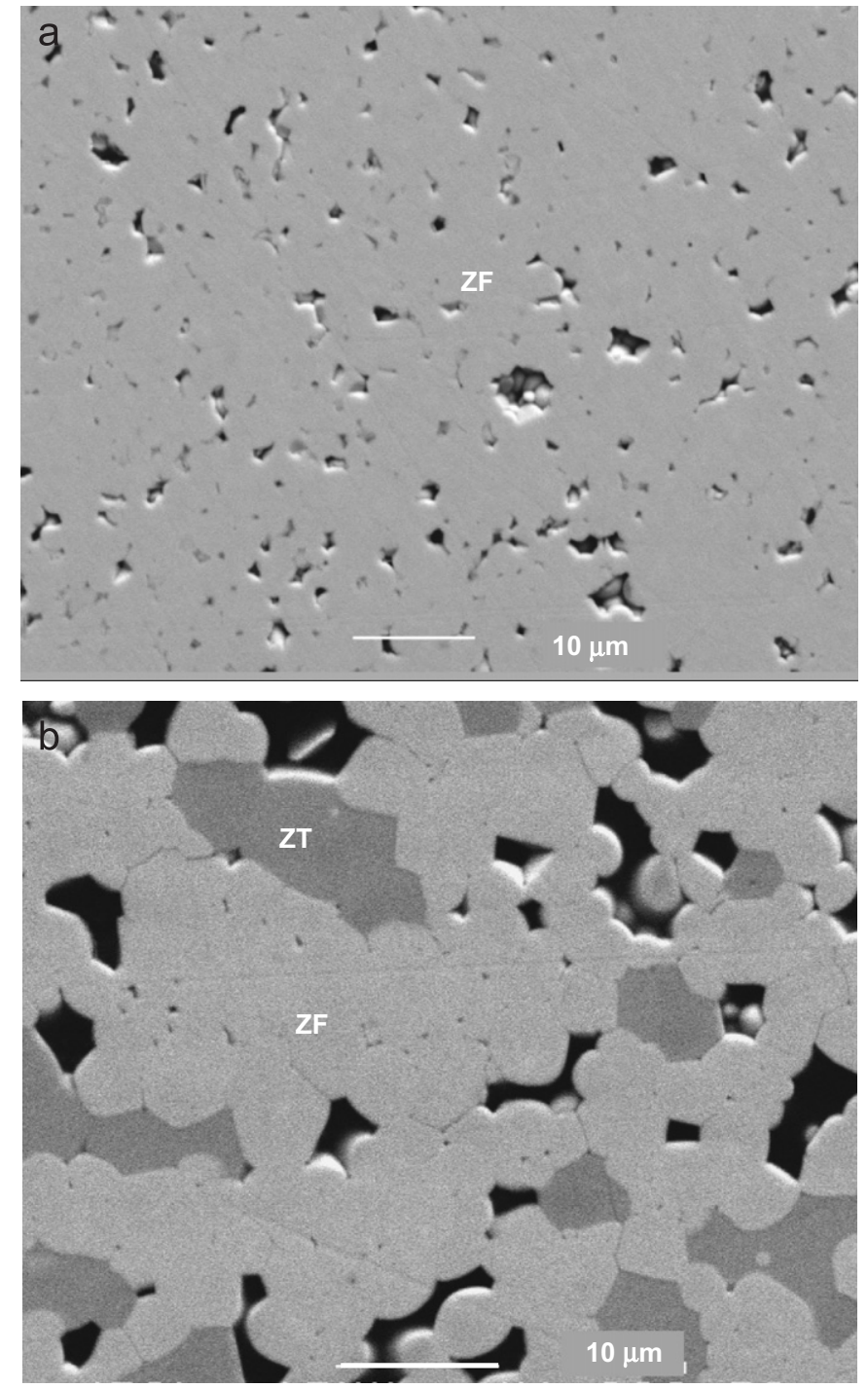

Fig. 1. Backscattered electron images of polished samples of zirconium titanate with $\mathrm{M}$-fergusonite structure $\left(Z_{\mathrm{F}}\right)$ and scrutinyite structure (ZT). (a) Sample G-661, (b) Sample G-534 (compare Table 1).

represents the tetragonal compound $\mathrm{Zr}_{3} \mathrm{TiO}_{8}$. [This is the $\mathrm{Ti}$ analogue of the compound $\mathrm{Zr}_{3} \mathrm{GeO}_{8}$. The two cations are in an arrangement corresponding to an ordered version of the scheelite structure (Fig. 4), with the tetrahedral site split into two distinct sites. However, the oxygens are moved so as to change the overall symmetry from $I 4_{1}$ for ordered scheelite to $I-42 \mathrm{~m}$.] With increasing $\mathrm{TiO}_{2}$-content, the main peak (112) of $\mathrm{Zr}_{3} \mathrm{TiO}_{8}$ broadens, decreases in height, and eventually splits in two, marking a chemically controlled phase transition in the $\mathrm{ZrO}_{2}-\mathrm{TiO}_{2}$ system. The second scan $\left(26.6 \mathrm{~mol}^{\%} \mathrm{TiO}_{2}\right)$ was interpreted to have the $\mathrm{Zr}_{3} \mathrm{TiO}_{8}$ structure in Troitzsch [12] because the peak splitting is so minor that it was not resolved with the XRD method employed. In the light of the present dataset, this sample is reinterpreted as a mix of $\mathrm{Zr}_{3} \mathrm{TiO}_{8}$ and the unknown phase investigated here. 


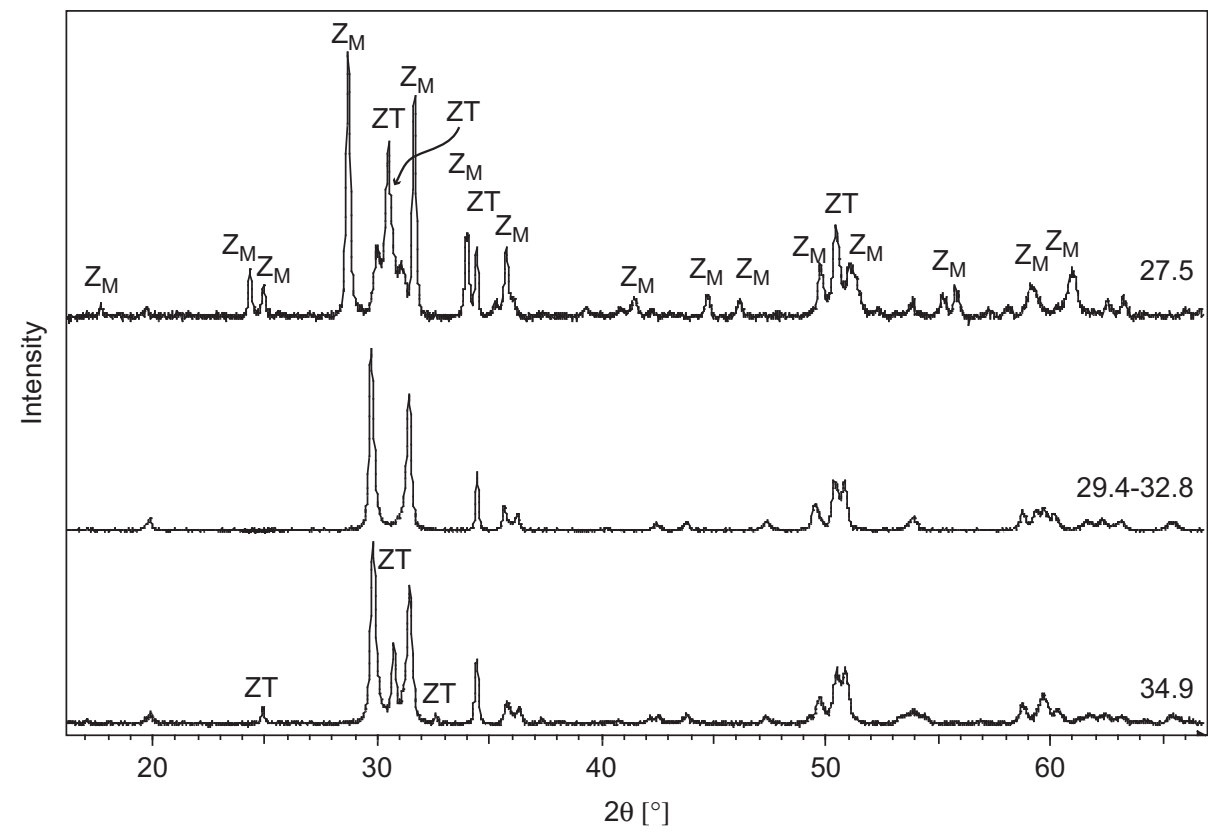

Fig. 2. X-ray diffraction patterns of zirconium titanate samples with different $\mathrm{TiO}_{2}$ contents [mol\%]. The second scan (G-661, 32.8 mol\%) is representative also for samples G-655 (29.4) and G-660 (32.2). Peaks other than those of the ordered M-fergusonite structure are indicated. Abbreviations as in Table 1.

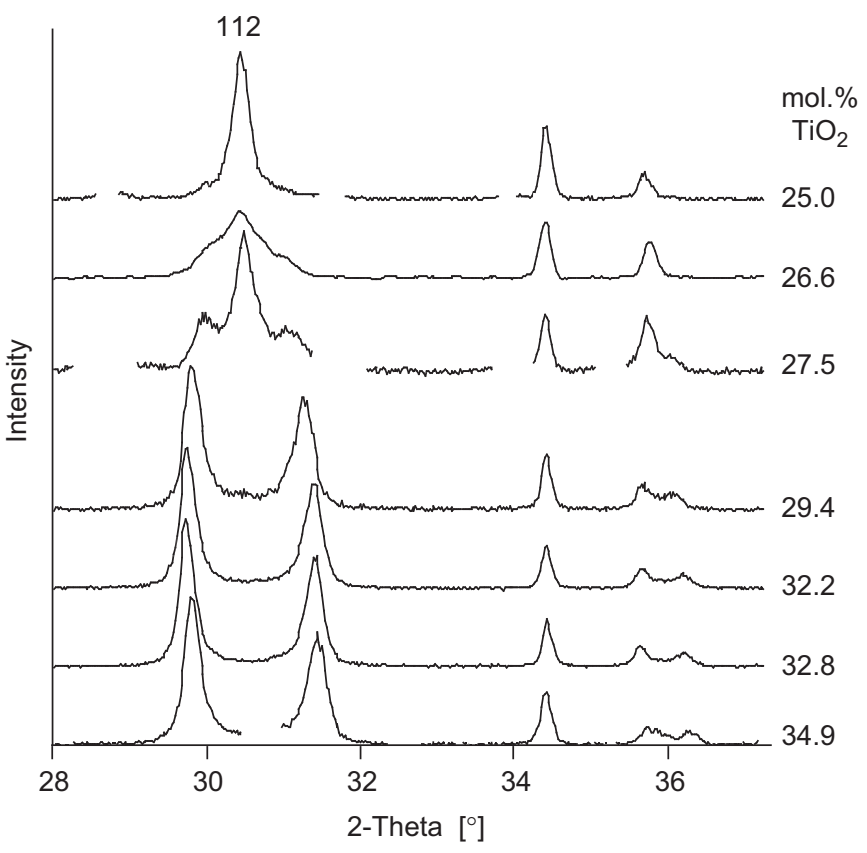

Fig. 3. Main peaks in the X-ray diffraction patterns of zirconium titanate, showing the transition from tetragonal $\mathrm{Zr}_{3} \mathrm{TiO}_{8}$ (top) to the monoclinic, ordered $\mathrm{M}$-fergusonite structure with increasing $\mathrm{TiO}_{2}$ content. Peaks of other phases were omitted for clarity. The two upper scans are from [12].

\subsection{Crystal structure}

The powder XRD pattern of the unidentified phase is topologically identical to that of monoclinic M-fergusonite, also known in mineralogy as fergusonite-beta $\left(\mathrm{YNbO}_{4}\right)$, which has a distorted variant of the fluorite structure with space group $C 2 / c[22,24]$ (Figs. 5a and 6). This $A B X_{4}$
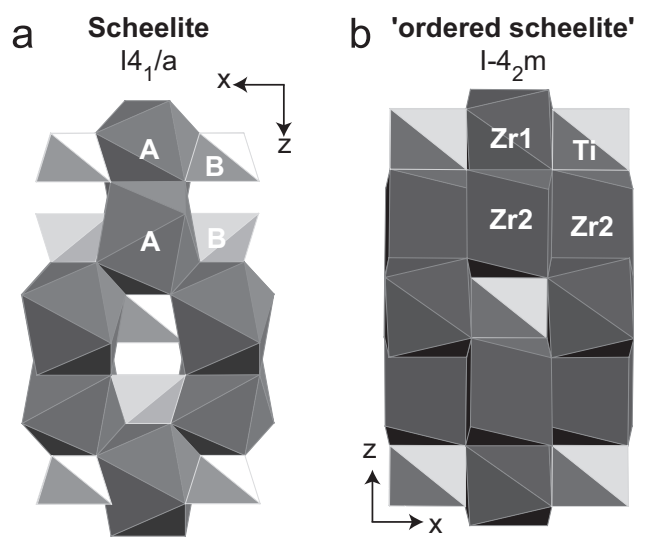

Fig. 4. (a) Scheelite $\left(\mathrm{CaWO}_{4}\right)$ structure [24-26]. (b) Crystal structure of $\mathrm{Zr}_{3} \mathrm{TiO}_{8}$ [12] based on an ordered scheelite structure. Note that the ordering pattern is similar to that of the slightly more $\mathrm{TiO}_{2}$-rich monoclinic compound (Fig. 5b).

structure is characterized by two distinct cation sites with 8-fold $(A)$ and 6-fold $(B)$ coordination by oxygen, eminently suitable for a $\mathrm{Zr}-\mathrm{Ti}$ compound. The stoichiometry of the compounds under investigation, however, differs from $A B X_{4}$ by a significant surplus of $\mathrm{Zr}^{4+}$ ions (Table 1), thus requiring at least one of the sites in the M-fergusonite structure to be of mixed occupation. Since the radius of $\mathrm{Zr}^{4+}$ permits both 8-fold and 6-fold coordination, while $\mathrm{Ti}^{4+}$ is restricted to 6-fold coordination or lower, $\mathrm{Zr}$ can be expected to be concentrated on site $A$, while $\mathrm{Ti}$ and the remaining $\mathrm{Zr}$ occupy site $B$ (Fig. 5a).

\subsubsection{Space group}

TEM work revealed a more complex picture of the samples than did powder XRD, with diffraction patterns 
and microstructures varying slightly from grain to grain. This is not surprising given that after equilibration at high pressures and temperatures the samples were cooled to atmospheric conditions, causing every grain in the sample to adjust to the new conditions, potentially inducing phase transitions, lattice strain, twinning and/or exsolution.

The overwhelming majority of the electron diffraction patterns of samples G-655, G-660 and G-661 observed with TEM are consistent with a $C$-centred space group in that reflections $h+k=2 n+1$ are absent (Fig. 7a-c). The requirement of a $c$-glide parallel (010) $(h 0 l$ with $l=2 n)$ however is contradicted by the presence of 001 and -201 reflections (Figs. 7a and c), indicating that the symmetry is lower than $C 2 / c$ that was suggested by the M-fergusonite XRD pattern (Fig. 6). Possible subgroups of $C 2 / c$ without

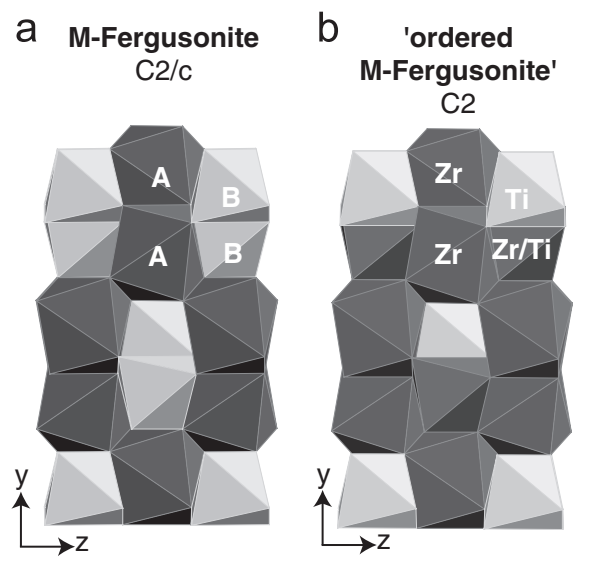

Fig. 5. Crystal structure of zirconium titanate with $27.5-35 \mathrm{~mol} \% \mathrm{TiO}_{2}$. (a) As refined in present study with $\mathrm{M}$-fergusonite structure, with site $A$ occupied predominantly with $\mathrm{Zr}$, and site $B$ with a random mix of $\mathrm{Ti}$ and $\mathrm{Zr}$ (Table 3). (b) Actual cation ordering pattern of this compound as indicated by superstructure reflections (Fig. 7c), resulting in the splitting of site $B$ into two distinct sites. Note that in the absence of a refinement with space group $C 2$ the coordination of the three sites is the same as in (a). a $c$-glide are $C 2, P 2 / n$, and $P 2_{1} / n$. Apart from the $c$-glide, also the presence of an $n$-glide $(h 0 l$ with $h+l=2 n)$ is contradicted by reflections such as -201 , leaving $C 2$ as the only possible space group for this new compound. This suggests that the parent M-fergusonite structure shows a certain degree of cation order on site $B$, resulting in a total of three different cation sites occupied by $\mathrm{Zr}$, Ti, and $\mathrm{Zr}+\mathrm{Ti}$, respectively (Fig. 5b). Note that this ordering pattern in the M-fergusonite structure, with most of the Ti concentrated on one site, is similar to that of the tetragonal compound $\mathrm{Zr}_{3} \mathrm{TiO}_{8}$ (Fig. 4b).

In very rare cases, $h+k=2 n+1$ reflections violated $C$-centring, indicating a different space group for these grains compared to the majority of the sample (Fig. 7d). This was ignored in the structure refinement below, on the assumption that these cases are so infrequent that they do not contribute to the XRD pattern significantly enough to be modelled.

\subsubsection{Structure refinement}

Rietveld refinement of the crystal structure with space group $C 2$ and its three distinct cation sites was not stable, and did not yield robust atomic parameters, probably because the 001 and -201 peaks are not strong enough to show in the XRD pattern (Fig. 6). Therefore, this study presents the refinement of the new $\mathrm{ZrTiO}_{4}$ compound based on the M-fergusonite structure with space group $C 2 / c$, emphasizing that one of the cation sites seems to be at least partly ordered in agreement with space group $C 2$. The resulting unit-cell dimensions are shown in Table 2 (see also Fig. 11).

The following problems were encountered during Rietveld refinement. In all samples, peak (040) (Fig. 6) was narrower than most others, making its intensity difficult to fit (Fig. 8). Moreover, the broadening of some of the other peaks was asymmetric, as seen for the two main peaks, each of which shows a shoulder towards the other (Fig. 8,

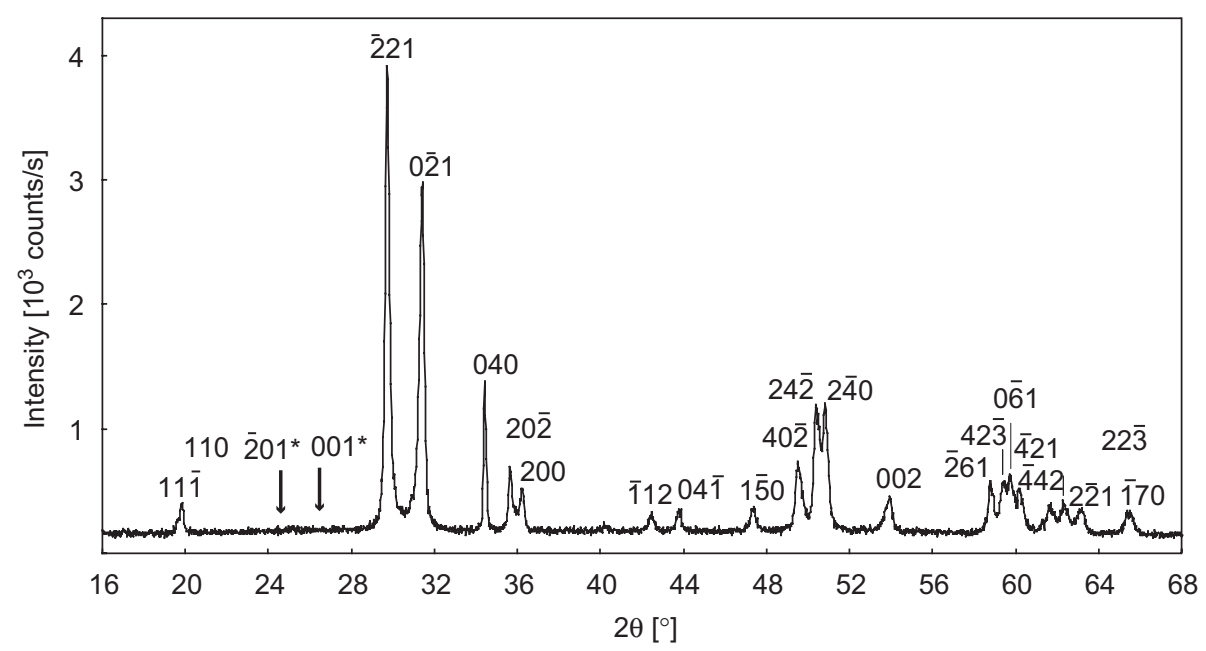

Fig. 6. Powder X-ray diffraction pattern of synthetic zirconium titanate ( $32.8 \mathrm{~mol} \% \mathrm{TiO}_{2}$, sample G-661) indexed with ordered $\mathrm{M}$-fergusonite structure. Note that superstructure peaks $(*) 001$ and -201 (cf. Fig. 7c) are below detection limit of XRD for all samples of this study. 

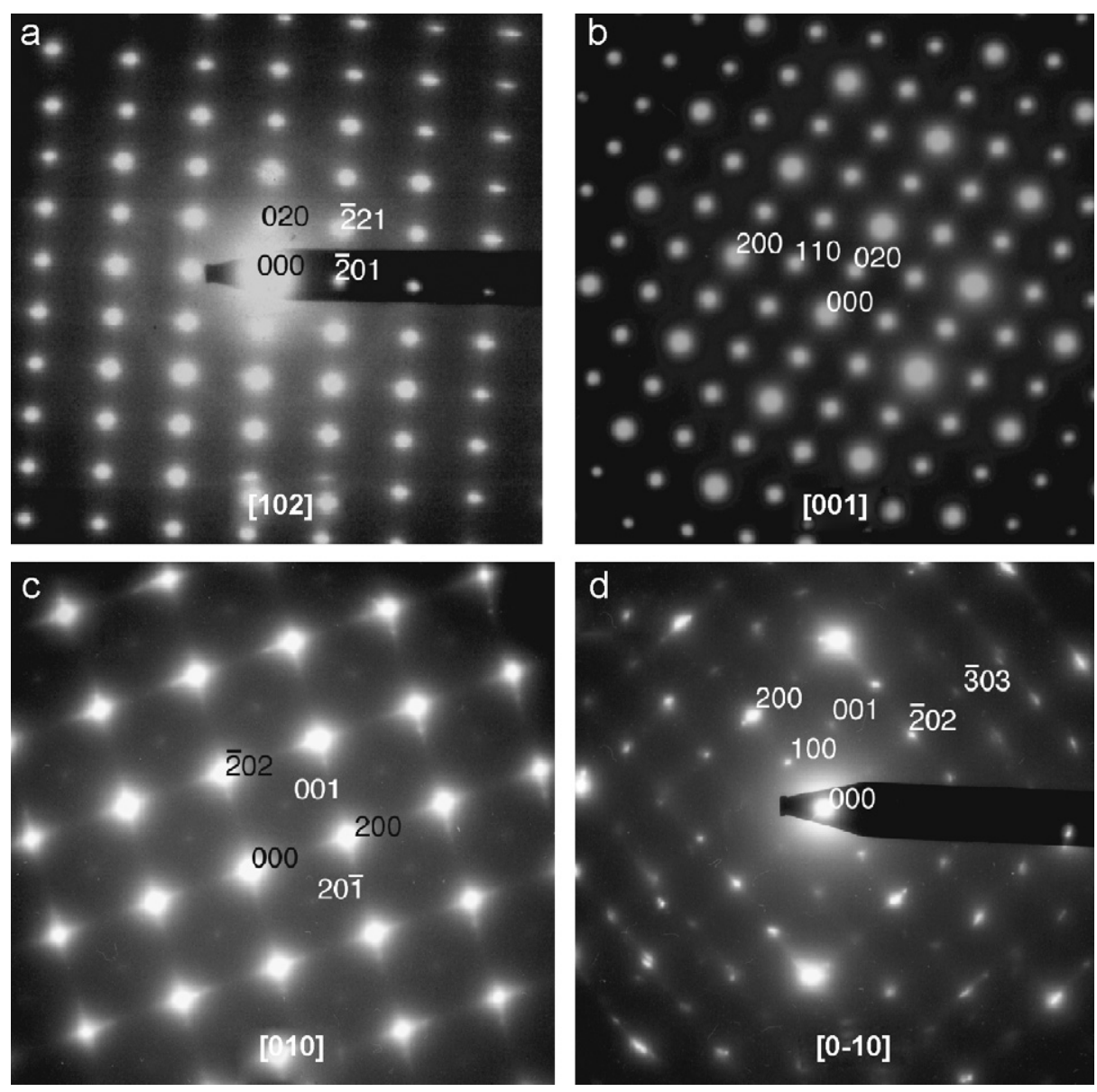

Fig. 7. Electron diffraction patterns of zirconium titanate with ordered M-fergusonite structure (a) viewed along zone [102] (sample G-660), (b) zone [001] (G-655), (c) zone [010] (G-655). Superstructure reflections $\{001\}$ and $\{20-1\}$ indicate cation ordering on site $B$ (cf. Fig. 5). Streaking of diffraction spots is probably due to domain boundaries. (d) Grains showing $\{100\}$ and $\{-101\}$ reflections that violate the proposed structure model are extremely rare (G-655).

Table 2

Unit cell dimensions of zirconium titanate with ordered M-fergusonite structure $\left(Z_{\mathrm{F}}\right)$

\begin{tabular}{|c|c|c|c|c|c|}
\hline$Z_{\mathrm{F}}$ composition $\left[\mathrm{mol} \% \mathrm{TiO}_{2}\right]$ & $a[\AA]$ & $b[\AA]$ & $c[\AA]$ & $\beta\left[^{\circ}\right]$ & $V\left[\AA^{3}\right]$ \\
\hline 27.5 & $7.267(20)$ & $10.435(3)$ & $5.023(11)$ & $136.45(12)$ & $262.44(92)$ \\
\hline 29.4 & $7.339(3)$ & $10.427(1)$ & $5.048(2)$ & $137.24(2)$ & $262.29(17)$ \\
\hline 32.2 & $7.355(2)$ & $10.4238(7)$ & $5.048(1)$ & $137.55(1)$ & $261.22(10)$ \\
\hline 32.8 & $7.361(2)$ & $10.4199(6)$ & $5.052(1)$ & $137.62(1)$ & $261.20(9)$ \\
\hline 34.9 & $7.340(2)$ & $10.429(1)$ & $5.040(1)$ & $137.55(1)$ & $260.40(12)$ \\
\hline
\end{tabular}

insert). This could be attributed to chemical inhomogeneity of the sample, as the position of the two main peaks is strongly $\mathrm{TiO}_{2}$-dependent (Fig. 3). At the same time, reflection (040) is relatively independent of composition, explaining the differences in peak width across the scan. Since the SEM data indicate only very small variations in the samples of $\pm 0.1-1.8 \mathrm{~mol} \%$, the compositional differences causing the peak broadening must occur between domains smaller than the SEM analytical resolution (about $3 \mu \mathrm{m})$. Such domains $(>20 \mathrm{~nm}$ ) were identified with TEM as discussed below. In order to minimize the effect of sample inhomogeneity on structural parameters, a sample composition of $32 \mathrm{~mol} \% \mathrm{TiO}_{2}$ was targeted for Rietveld refinement (sample G-661), because the unit-cell dimensions vary least in this compositional range.

It was found that slow cooling improved the sharpness of the peaks, as demonstrated by the full-width-at-halfmaximum of the two main peaks of a quenched sample G-655 (0.265 and $\left.0.297^{\circ} 2 \theta\right)$ compared to those of the slowly cooled sample G-661 (0.218 and $\left.0.247^{\circ} 2 \theta\right)$. This effect of cooling rate on sharpness of selected peaks was also observed in the tetragonal compound $\mathrm{Zr}_{3} \mathrm{TiO}_{8}$ [12], and was interpreted as due to an increase of cation order in that crystal structure (Fig. 4). This is in agreement with the present study, suggesting that ordering plays a role in the stabilization of the monoclinic compound (Fig. 5b). 


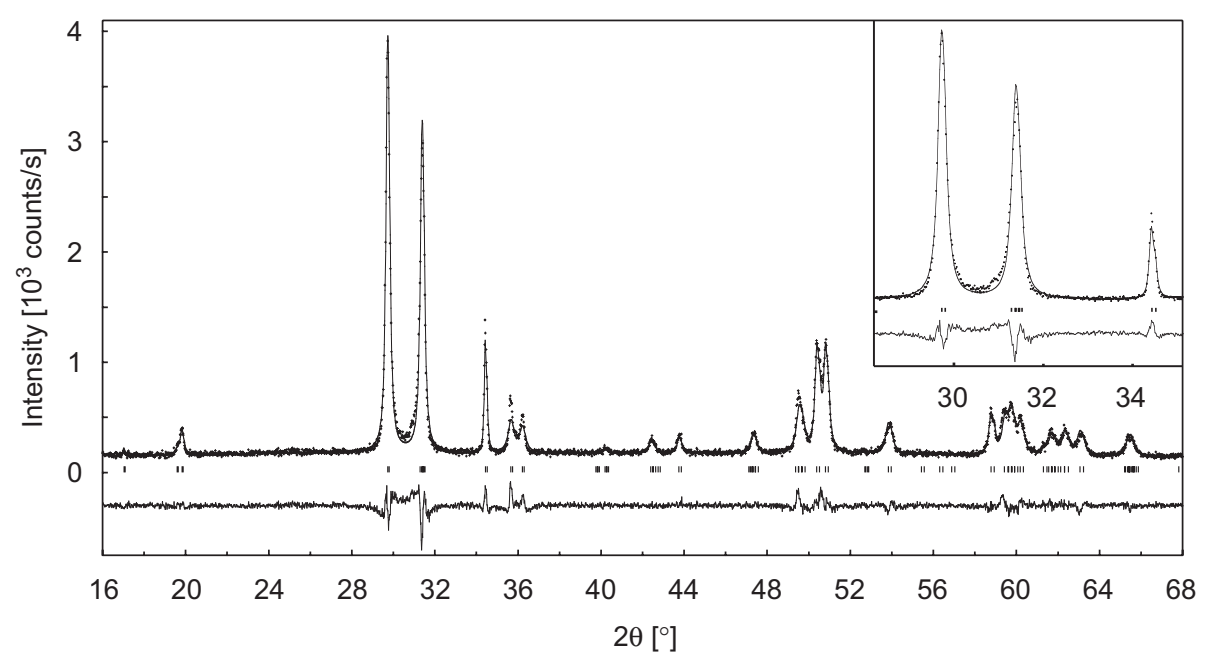

Fig. 8. Rietveld refinement profiles of synthetic zirconium titanate $\left(32.8 \mathrm{~mol} \% \mathrm{TiO}_{2}\right.$, sample G-661) with ordered M-fergusonite structure. Observed data (dots), calculated profile (upper line), difference profile (lower line), peak positions (bars). Insert shows enlargement of main peaks.

The sample most suited for refinement was G-661, which was cooled very slowly and had the narrowest main peaks. Refinement results of two different approaches are summarized in Table 3. First, the cation distribution was assumed to be $\mathrm{Zr}$ on site $A$, and $66 \% \mathrm{Ti}$ and $34 \% \mathrm{Zr}$ on site $B$. While this resulted in a fair fit to the XRD pattern (Fig. 8; Table 3, column 1), it also implied an unacceptably small bond length $B-\mathrm{O} 2$ of $1.81 \AA$ and poor bond valence sums for the cations $(3.49,4.57)$. In a second approach, a small amount of cation mixing was allowed also on site $A$, whereby a distribution of $10 \% \mathrm{Ti}$ on site $A$ and $56 \% \mathrm{Ti}$ on site $B$ resulted in a significantly improved statistical fit (Table 3, column 2). Most importantly, this slight deviation from fully ordered cation distribution resulted in much more realistic bond valence sums $(3.87,4.01)$ and an acceptable, though small, $B-\mathrm{O} 2$ bond length of $1.872 \AA$.

However, neither of these refinements could fit the strong peak asymmetry (Fig. 8), attributed above to sample inhomogeneity. Future work could aim at the synthesis of this compound with co-precipitation methods in order to minimize sample inhomogeneity. Neutron diffraction could be used to confirm oxygen positions.

\subsubsection{Diffuse scattering and microstructure}

Diffuse scattering in the form of streaking was present in diffraction patterns of all investigated samples. Streaking of diffraction spots was most strongly observed along or sub-parallel to $\langle 200\rangle^{*}$ and $\langle 20-2\rangle^{*}$ (Fig. 7c), but was also present along $\langle 110\rangle^{*},\langle-110\rangle^{*},\langle-111\rangle^{*}$, and $\langle 2-4-2\rangle^{*}$. The two perpendicular orientations of diffuse streak in Fig. $7 \mathrm{c}$ are strongly reminiscent of those associated with tweed texture in other systems [27, Fig. 8.23,28], and in fact, some images were taken of the grains that show faint one- or two-dimensional diffuse modulations that resemble spinodal and tweed textures. While these modulated microstructures may well be precursors to the twins that are described below, it is clear that a wide range of combinations of microstructure and bulk lattice strain may be quenched in, in this compound.

Fig. 9 shows that streaking parallel to $\langle 200\rangle^{*}$ could be related to the sharp boundaries of irregularly-spaced lamellar domains ( $>20 \mathrm{~nm}$ thick) in twin orientations relative to their neighbours. The twinning plane is (200), and is slightly inclined $\left(\sim 5^{\circ}\right)$ to the domain boundary (composition plane) in the case shown in Fig. 9c. The slight mismatch between twin plane and domain boundary could be due to a small compositional difference between the adjacent domains, which would affect the unit-cell dimensions, and thus require a coherent boundary to be tilted relative to the twin plane. The existence of such a composition difference is demonstrated by the slightly different $d$-spacings for the split diffraction spots from the two twin individuals, resulting in a subtle asymmetry of the 'twin' pattern (Figs. 9 and 10).

Such 'asymmetric twinning' was frequently observed, with twin planes either (200) (Fig. 9) or (20-2) (Fig. 10); the normals to these planes correspond to the dominant directions of diffuse scattering observed (Fig. 7c). Variation in composition up to about $8 \mathrm{~mol} \%$ between adjacent domains was estimated based on the observed variations in $d$-spacing, and would be consistent with the peak asymmetry seen with XRD and discussed above. The coincidence of twin boundary with compositional boundary is notable: 'asymmetric twins' combine features of both conventional twins and exsolution lamellae. These microstructures are not without precedent in other systems, however, as will be seen below.

Lamellar reflection twins with the same orientation relationship as those presented here were previously reported for synthetic fergusonite $\left[\mathrm{YNbO}_{4}\right]$, and were suggested to have been induced by the tetragonal-monoclinic (scheelite to M-fergusonite) phase transition during cooling [29]. This phase transition is a 2 nd order, displacive and reversible transformation corresponding to the $B_{\mathrm{g}}$ representation of the 
Table 3

Crystal structure refinement results

\begin{tabular}{|c|c|c|c|}
\hline $\begin{array}{l}\text { Sample } \\
\text { Ti-occupancy }\end{array}$ & $\begin{array}{l}A \\
B\end{array}$ & $\begin{array}{l}\text { G-661 } \\
0.00 \\
0.66\end{array}$ & $\begin{array}{l}\text { G-661 } \\
0.10 \\
0.56\end{array}$ \\
\hline \multicolumn{4}{|c|}{ Refinement statistics } \\
\hline$R_{w p}^{1}$ & 9.16 & 9.14 & \\
\hline$R_{\text {Bragg }}^{2}$ & 2.68 & 2.64 & \\
\hline$R_{F}^{3}$ & 1.61 & 1.55 & \\
\hline \multicolumn{4}{|c|}{ Unit-cell parameters } \\
\hline$a$ & {$[\AA]$} & $7.362(2)$ & $7.361(2)$ \\
\hline$b$ & {$[\AA]$} & $10.4202(6)$ & $10.4200(6)$ \\
\hline$c$ & {$[\AA]$} & $5.052(1)$ & $5.052(1)$ \\
\hline$\beta$ & {$\left[{ }^{\circ}\right]$} & $137.62(1)$ & $137.62(1)$ \\
\hline$V$ & {$\left[\AA^{3}\right]$} & $261.21(9)$ & $261.21(9)$ \\
\hline \multicolumn{4}{|l|}{ Atom positions } \\
\hline \multirow[t]{3}{*}{$A$} & $x$ & 0.0 & 0.0 \\
\hline & $y$ & $0.3794(5)$ & $0.3796(5)$ \\
\hline & $z$ & 0.25 & 0.25 \\
\hline \multirow[t]{3}{*}{$B$} & $x$ & 0.0 & 0.0 \\
\hline & $y$ & $0.8597(4)$ & $0.8605(4)$ \\
\hline & $z$ & 0.25 & 0.25 \\
\hline \multirow[t]{3}{*}{$\mathrm{O} 1$} & $x$ & $0.223(5)$ & $0.215(4)$ \\
\hline & $y$ & $0.7780(7)$ & $0.7795(7)$ \\
\hline & $z$ & $0.226(7)$ & $0.199(6)$ \\
\hline \multirow[t]{3}{*}{$\mathrm{O} 2$} & $x$ & $0.247(2)$ & $0.265(2)$ \\
\hline & $y$ & $0.9626(8)$ & $0.9630(9)$ \\
\hline & $z$ & $0.672(3)$ & $0.693(3)$ \\
\hline \multicolumn{4}{|c|}{ Thermal parameters } \\
\hline \multirow[t]{4}{*}{$B\left[\mathrm{~A}^{2}\right]$} & $A$ & $0.7(1)$ & $0.2(1)$ \\
\hline & $B$ & $0.1(2)$ & $1.4(2)$ \\
\hline & $\mathrm{O} 1$ & $1.5(2)$ & $1.3(2)$ \\
\hline & $\mathrm{O} 2$ & $1.5(2)$ & $1.3(2)$ \\
\hline \multicolumn{4}{|c|}{ Bond valence sums } \\
\hline & $A$ & 3.49 & 3.87 \\
\hline & $B$ & 4.57 & 4.01 \\
\hline & $\mathrm{O} 1$ & 1.97 & 1.94 \\
\hline & $\mathrm{O} 2$ & 2.07 & 2.00 \\
\hline \multicolumn{4}{|l|}{ 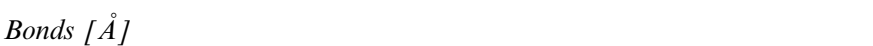 } \\
\hline & $A-\mathrm{O} 1$ & $2.219 \times 2$ & $2.181 \times 2$ \\
\hline & & $2.310 \times 2$ & $2.256 \times 2$ \\
\hline & $A-\mathrm{O} 2$ & $2.171 \times 2$ & $2.116 \times 2$ \\
\hline & & $2.292 \times 2$ & $2.243 \times 2$ \\
\hline & $B-\mathrm{O} 1$ & $1.931 \times 2$ & $1.971 \times 2$ \\
\hline & & $2.291 \times 2$ & $2.377 \times 2$ \\
\hline & $B-\mathrm{O} 2$ & $1.809 \times 2$ & $1.872 \times 2$ \\
\hline
\end{tabular}

scheelite point group $4 / m$, with a lattice strain component dominated by simple shear in the $\mathbf{x y}$ plane. It can be induced by changes in $P, T$ or applied shear stress. The twins in $\mathrm{ZrTiO}_{4}$ documented in the present study could thus be an indication that the M-fergusonite compound is tetragonal at high pressures and temperatures, where it adopts the $\mathrm{Zr}_{3} \mathrm{TiO}_{8}$ structure. During decompression and cooling, it may undergo a tetragonal-monoclinic phase transition, which induces twinning along (200) and (-202) to reduce the macroscopic strain of the crystals. The observed compositional differences between the twinned domains suggest that twin boundaries form at sites of strong compositional gradients, which may be pre-existing, or form during spinodal decomposition on annealing or cooling.

\section{Structural evolution with Ti content}

Fig. 11 shows how the unit-cell dimensions of $\mathrm{ZrTiO}_{4}$ evolve with increasing $\mathrm{TiO}_{2}$ content across four different distorted fluorite structures, all referred to the axial setting of baddeleyite (monoclinic $\mathrm{ZrO}_{2}$ ), or tetragonal scheelite cell with $c$ halved. The baddeleyite structure with 7-fold coordinated cations is stable up to about $25 \mathrm{~mol} \% \mathrm{TiO}_{2}$ (the exact composition depends on cooling rate), where two of its unit-cell dimensions become near-identical, and the $\beta$ angle drops towards $90^{\circ}$ [12]. At this composition, all cell dimensions change abruptly, the $c$ dimension doubles due to cation ordering, and the tetragonal compound $\mathrm{Zr}_{3} \mathrm{TiO}_{8}$ is stabilized when cooled slowly, accommodating $\mathrm{Ti}$ in 6-fold and $\mathrm{Zr}$ in 8-fold coordination. Above $25 \mathrm{~mol} \%$ $\mathrm{TiO}_{2}$, the tetragonal structure distorts again, this time continuously, to form a different monoclinic compound with the M-fergusonite structure, again with two cation sites of 6-fold and 8-fold coordination. Referring to the original baddeleyite cell with monoclinic angle $\beta$, it is now the $\gamma$ angle that deviates from $90^{\circ}$. Above $42 \mathrm{~mol} \% \mathrm{TiO}_{2}$, after another discontinuous change in cell dimensions, $\mathrm{ZrTiO}_{4}$ is stable in the orthorhombic scrutinyite structure, where all cations occupy 6-fold coordinated sites independent of whether the compound is cation-ordered [17] or disordered [30].

The structural relationship between $\mathrm{ZrTiO}_{4}$ with ordered M-fergusonite structure and neighbouring $\mathrm{Zr}_{3} \mathrm{TiO}_{8}$ is one of continuous phase transition by simple shear and small atomic displacements, as discussed above. However, structural similarities also exist between the ordered M-fergusonite phase and the scrutinyite structure compound, despite the discontinuous phase change between 35 and $42 \mathrm{~mol} \% \mathrm{TiO}_{2}$. The basic building block of $\mathrm{ZrTiO}_{4}$ with scrutinyite structure is that of a kinked, edge-sharing chain of octahedra occupied with $\mathrm{Zr}$ and $\mathrm{Ti}$. The more $\mathrm{Zr}$ rich the compound, the more displaced are the cations from the octahedral centre on average, significantly reducing the distance between the 6-fold coordinated cation and two non-bonded oxygens from a neighbouring chain $\left(3.017 \AA\right.$ at $42 \mathrm{~mol} \% \mathrm{TiO}_{2}$ ) [23]. This was interpreted as the evolution of the average structure towards 8-fold coordination, as seen in tetragonal $\mathrm{ZrO}_{2}$. A similar kinked chain is found in $\mathrm{ZrTiO}_{4}$ with $\mathrm{M}$-fergusonite structure (as refined in $C 2 / c$ ) along [-101], made up of edge-sharing site $B$ octahedra (Fig. 12). Here, too, the cations are strongly displaced from the octahedral centre, and the distances to two additional oxygens from neighbouring chains even shorter $(2.819 \AA)$ than for the scrutinyite phase. The extremely short $B-\mathrm{O} 2$ bond is explained in this structural context, since this is caused by the movement of cation $B$ away from the shared $\mathrm{O} 1-\mathrm{O} 1$ edge (Fig. 12). Thus, the M-fergusonite compound extends the trend identified in the 

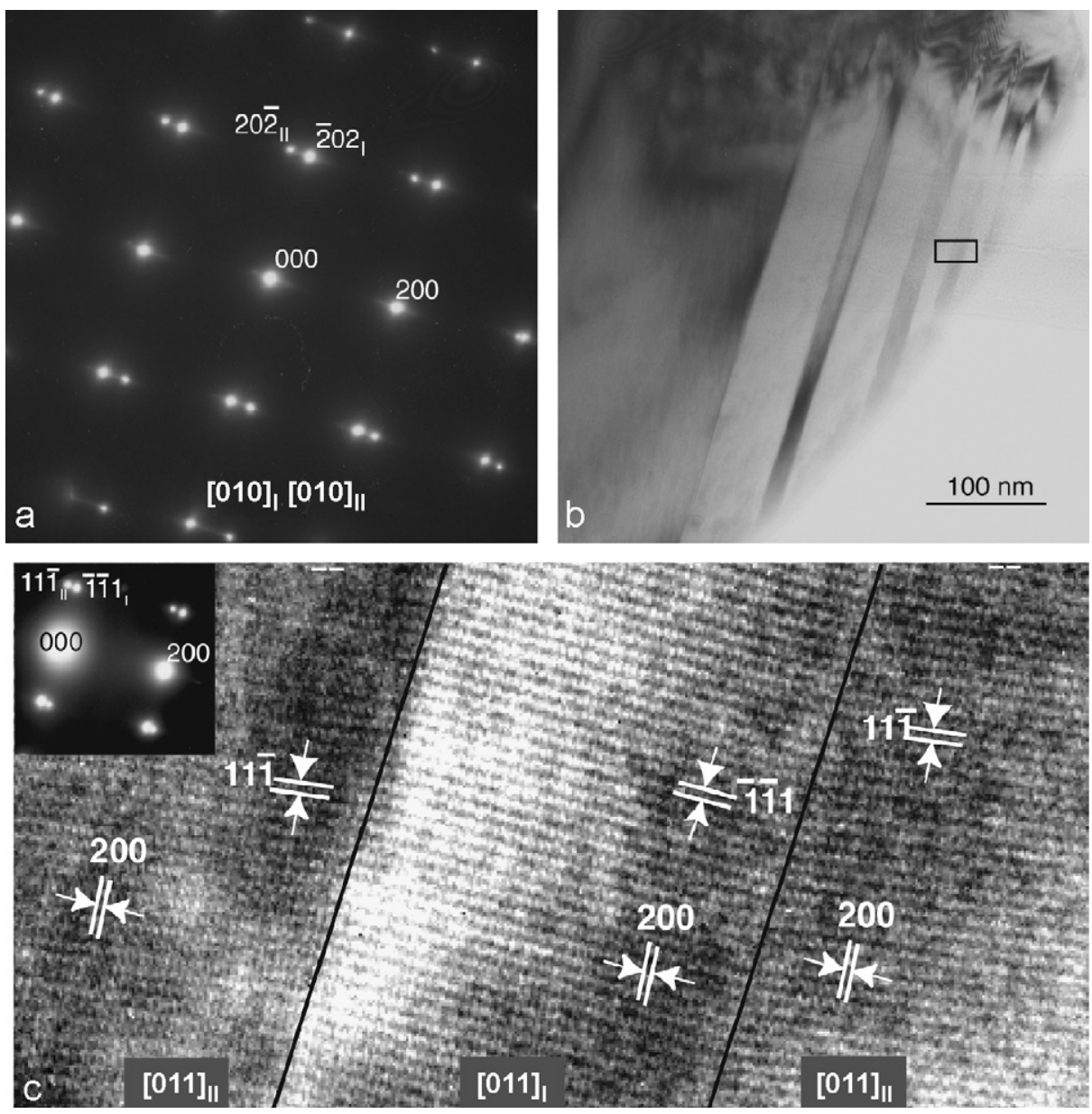

Fig. 9. Twin domains I and II in zirconium titanate with ordered M-fergusonite structure (sample G-661). (a) Diffraction pattern along zones [010] $]_{\mathrm{I}}$ and $[0-10]_{\text {II }}$ (b) Bright-field image of lamellar twin domains. To enhance contrast the BFI was taken at an angle of $3^{\circ}$ to the diffraction pattern, but is shown here in the orientation corresponding to (a). (c) Lattice image of framed area in (b) across two twin boundaries (marked as black lines), viewed along zones $[0-1-1]_{\mathrm{I}}$ and $[011]_{\mathrm{II}}$. Corresponding diffraction pattern is shown as insert.

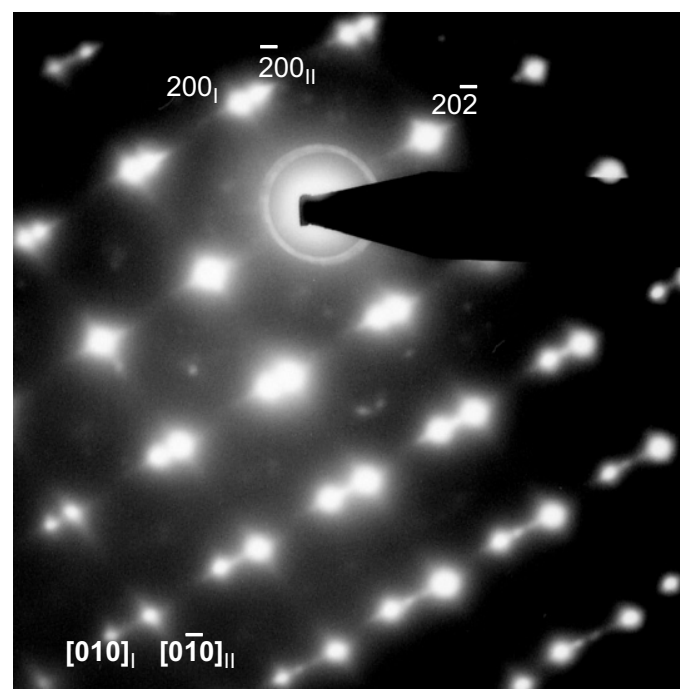

Fig. 10. Diffraction pattern of two domains related by twinning, viewed along zones $[010]_{\mathrm{I}}$ and $[0-10]_{\mathrm{II}}$. Subtle differences in $d$ spacing indicate that domains have slightly different composition. scrutinyite structure [23], and represents another intermediate step between 6 -fold coordination of the cations in $\mathrm{TiO}_{2}$-dominated compounds $\left(\mathrm{ZrTiO}_{4}, \mathrm{TiO}_{2}\right)$ on the one hand, and 7-/8-fold coordination of $\mathrm{ZrO}_{2}$-rich phases on the other. While tetragonal $\mathrm{ZrO}_{2}$ with 8-coordinated $\mathrm{Zr}$ can only be stabilized with grain sizes significantly smaller than those of this study or by doping [31,32], the M-fergusonite compound, like $\mathrm{Zr}_{3} \mathrm{TiO}_{8}$, facilitates the stabilization of most of the $\mathrm{Zr}$ in 8-fold coordination by concentrating the smaller cation $\mathrm{Ti}$ predominantly on one site.

The unit cells of $\mathrm{Zr}_{3} \mathrm{TiO}_{8}$ and the M-fergusonite compound, both of which are ordered, are much more compact than those of the baddeleyite- and scrutinyitestructure phases in this system (Fig. 11b), consistent with their high-pressure synthesis. Ordering seems to decrease unit-cell size in this system, allowing for more efficient packing of the different sized cations. This phenomenon is also seen in $\mathrm{ZrTiO}_{4}$ with scrutinyite structure, the largest dimension of which decreases by up to $3 \%$ upon cation 


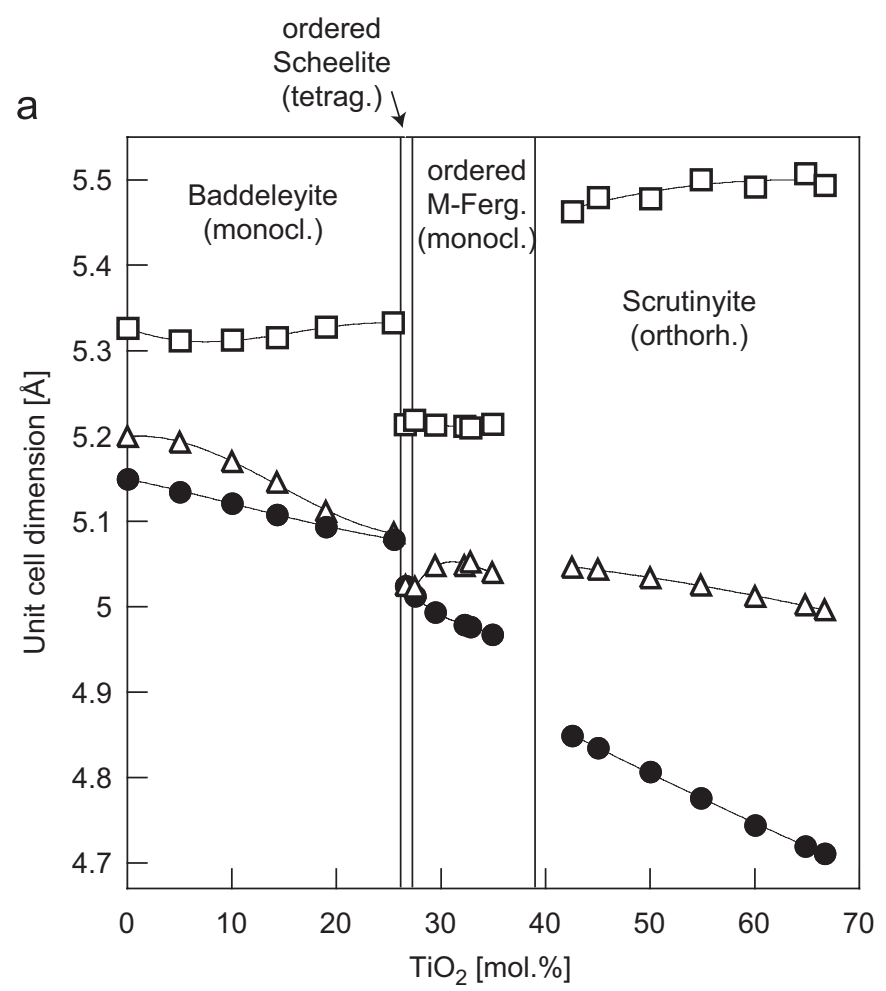

b

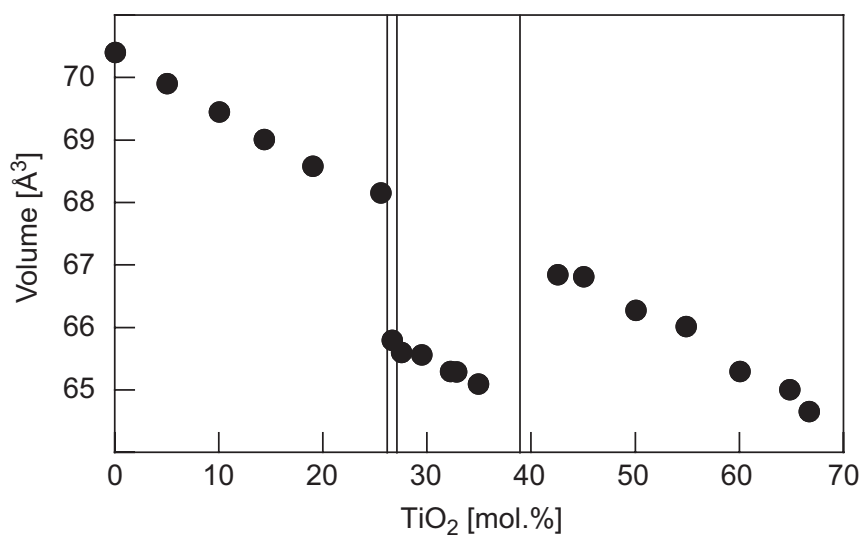

Fig. 11. (a) Evolution of crystal structure and unit-cell dimensions of $\mathrm{ZrO}_{2}-\mathrm{TiO}_{2}$ compounds with various distorted fluorite structures along the binary join at atmospheric conditions. For easier comparison all cells were chosen to refer to the baddeleyite cell; i.e. the longest dimension of the ordered compounds $\mathrm{Zr}_{3} \mathrm{TiO}_{8}$ and fergusonite structure was halved. Data for scrutinyite and baddeleyite structures from [23] and [12], respectively. (b) Plot of volume per oxygen atom.

ordering induced by slow cooling [13,17]. The stabilization of the small unit-cells of $\mathrm{Zr}_{3} \mathrm{TiO}_{8}$ and the M-fergusonite compound even after cooling to room temperature is in stark contrast to the behaviour of more $\mathrm{ZrO}_{2}$-rich compound with baddeleyite structure $\left(<26 \mathrm{~mol}_{0} \% \mathrm{TiO}_{2}\right)$, which undergoes the tetragonal-monoclinic phase transition during cooling. This phase change goes hand in hand with a significant increase in volume, which causes the run products to crack or disintegrate, thus posing a challenge to the manufacture of ceramics based on these compositions.

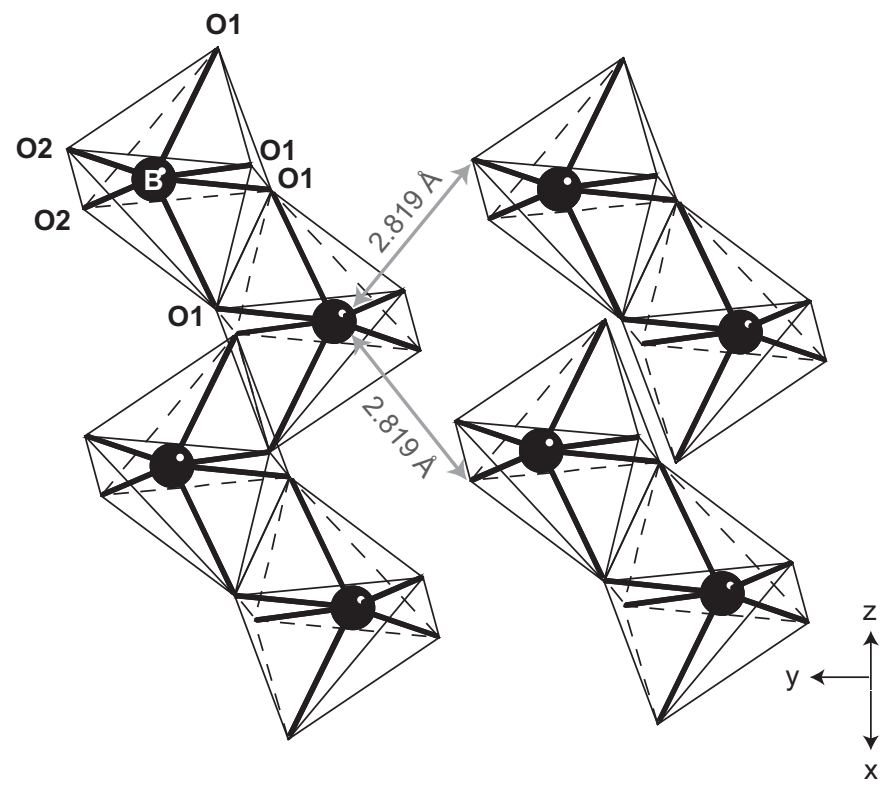

Fig. 12. Crystal structure detail of zirconium titanate $\left(33 \mathrm{~mol} \% \mathrm{TiO}_{2}\right)$ with M-fergusonite structure. Grey arrows indicate the short distance between cation $B$ and two non-bonded $\mathrm{O} 2$ oxygens of the neighbouring octahedral chains. Cation $A$ not shown.

\section{Conclusions}

High-pressure synthesis experiments quenched to ambient conditions resulted in the formation of a $(\mathrm{Zr}, \mathrm{Ti}) \mathrm{O}_{2}$ compound that can be regarded as 'new' with regards to composition $\left(28-35 \mathrm{~mol} \% \mathrm{TiO}_{2}\right)$ as well as structure (ordered M-fergusonite structure). To the authors' knowledge, the M-fergusonite structure is mostly adopted by $A^{3+} B^{5+} X_{4}$ compounds such as rare earth or yttrium niobates and tantalates. This study shows that the structure is also suitable for $\left(A^{4+}, B^{4+}\right)_{2} X_{4}$ of appropriate ionic radii and composition. Interestingly, in this case the ordered M-fergusonite structure was adopted by a compound that essentially had $A B_{2} X_{6}$ stoichiometry $\left(33 \mathrm{~mol} \% \mathrm{TiO}_{2}\right)$, but was obviously preferred over $A B_{2} X_{6}$ structures such as those of columbite-tantalite $(\mathrm{Fe}, \mathrm{Mn})(\mathrm{Nb}, \mathrm{Ta})_{2} \mathrm{O}_{6}$, the aeschynite and euxenite polymorphs of $\operatorname{REE}(\mathrm{Nb}, \mathrm{Ti})_{2} \mathrm{O}_{6}$, or most notably srilankite, $\mathrm{ZrTi}_{2} \mathrm{O}_{6}$.

We emphasize the unusual nature of the "asymmetric twinning" in this material, in which twin individuals do not necessarily have the same mean composition as their neighbours, and hence diffraction patterns of the individuals are not perfect mirror images in the twin plane. This unusual microstructure appears to be a consequence of metastable quenching of a system in which $\mathrm{Ti}-\mathrm{Zr}$ interdiffusion is very strongly coupled to lattice strain. We note that related microstructures have been observed in other systems. The stability of $1 A$ and $2 M$ polytypes of the aluminosilicate mineral sapphirine is strongly coupled to $\mathrm{Fe}^{2+}-\mathrm{Fe}^{3+}$ ratio, and redox reactions can result in large changes in cell parameters, loss of coherence of intergrowth and reorientation of phase boundaries [33]. Recently, a range of supposed 'c type' superstructures in calcite and 
dolomite have been explained in terms of intergrowth of lamellar (104) twins of calcite in either calcite or dolomite matrix [34].

Although ( $\mathrm{Zr}, \mathrm{Ti}) \mathrm{O}_{2}$ with ordered M-fergusonite structure was encountered as a quenched high-pressure phase, it is possible that it also forms at low pressures in very finegrained materials, such as those reacted by sol-gel annealing, ball milling, or thin film sputtering. For example, a monoclinic high-pressure form of $\mathrm{ZrTiO}_{4}$ was found to form by thin film sputtering, probably stabilized by the Gibbs-Thompson effect [9].

\section{Acknowledgments}

John Fitzgerald and Frank Brink are thanked for assistance during the TEM sessions, and two anonymous reviewers for their helpful comments. This work has been supported by an Australian Research Council Discovery Project Grant (DP 0559055) to David J. Ellis and Andrew G. Christy.

\section{References}

[1] O. Ohtaka, H. Fukui, T. Kunisada, T. Fujisawa, K. Funakoshi, W. Utsumi, T. Irifune, K. Kuroda, T. Kikegawa, Phys. Rev. B 63 (2001) 174108.

[2] G. Wolfram, H.E. Göbel, Mater. Res. Bull. 16 (1981) 1455-1463.

[3] F. Azough, R. Freer, C.-L. Wang, G.W. Lorimer, J. Mater. Sci. 31 (1996) 2539-2549.

[4] C.-L. Wang, H. Lee, F. Azough, R. Freer, J. Mater. Sci. 32 (1997) $1693-1701$.

[5] M. Dondi, F. Matteucci, G. Cruciani, J. Solid State Chem. 179 (2006) 233-246.

[6] M. Dondi, G. Cruciani, G. Guarini, F. Matteucci, M. Raimondo, Ceram. Int. 32 (2006) 393-405.

[7] C.R. Aita, M.D. Wiggins, R. Whig, C.M. Scanlan, M. GajdardziskaJosifovska, J. Appl. Phys. 79 (1996) 1176-1178.
[8] R.B. van Dover, L.F. Schneemeyer, R.M. Fleming, Nature 392 (1998) 162-164.

[9] C.R. Aita, J.D. DeLoach, V.V. Yakovlev, Appl. Phys. Lett. 81 (2002) $238-240$.

[10] R.S. Sorbello, J.D. DeLoach, C.R. Aita, P. Fejes, J. Vac. Sci. Technol. B 22 (2004) 2658-2662.

[11] F. Azough, A. Wright, R. Freer, J. Solid State Chem. 108 (1994) 284-290.

[12] U. Troitzsch, J. Am. Ceram. Soc. 89 (2006) 3201-3210.

[13] U. Troitzsch, D.J. Ellis, J. Mater. Sci. 40 (2005) 4571-4577.

[14] A.V. Shevchenko, L.M. Lopato, I.M. Maister, O.S. Gorbunov, Russ. J. Inorg. Chem. 25 (1980) 1379-1381.

[15] M. Stubicar, V. Bermanec, N. Stubicar, D. Kurdnovski, D. Krumes, J. Alloys Compd. 316 (2001) 316-320.

[16] S.X. Zhang, J.B. Li, J. Cao, H.Z. Zhai, B. Zhang, J. Eur. Ceram. Soc. 21 (2001) 2931-2936.

[17] A.E. McHale, R.S. Roth, J. Am. Ceram. Soc. 69 (1986) 827-832.

[18] U. Troitzsch, D.J. Ellis, Eur. J. Mineral. 16 (2004) 577-584.

[19] U. Troitzsch, A.G. Christy, D.J. Ellis, J. Am. Ceram. Soc. 87 (2004) 2058-2063.

[20] V.M. Khomenko, K. Langer, H. Rager, A. Fett, Phys. Chem. Miner. 25 (1998) 338-346.

[21] F. Izumi, T. Ikeda, Mater. Sci. Forum 321-324 (2000) 198-203.

[22] H. Weitzel, H. Schröcke, Z. Kristallogr. 152 (1980) 69-82.

[23] U. Troitzsch, A.G. Christy, D.J. Ellis, Phys. Chem. Miner. 32 (2005) 504-514.

[24] A.I. Komkov, Kristallographiya 4 (1959) 836-841.

[25] M.I. Kay, B.C. Frazer, I. Almodovar, J. Chem. Phys. 40 (1964) 504-506.

[26] A. Zalkin, D.H. Templeton, J. Chem. Phys. 40 (1964) 501-504.

[27] E.K.H. Salje, Phase Transitions in Ferroelastic and Co-elastic Crystals, Cambridge University Press, Cambridge, 1990.

[28] A. Putnis, S.A.T. Redfern, C.A. Fyfe, H. Strobl, Phys. Chem. Miner. 14 (1987) 446.

[29] C. Quinn, R. Wusirika, J. Am. Ceram. Soc. 74 (1991) 431-432.

[30] R.E. Newnham, J. Am. Ceram. Soc. 50 (1967) 216.

[31] T.K. Gupta, J.H. Bechthold, R.C. Kuznicki, L.H. Cadoff, B.R. Rossing, J. Mater. Sci. 12 (1977) 2421-2426.

[32] R.H.J. Hannink, P.M. Kelley, B.C. Muddle, J. Am. Ceram. Soc. 83 (2000) 461-487.

[33] A.G. Christy, Contrib. Mineral. Petrol. 103 (1989) 203-215.

[34] A.-K. Larsson, A.G. Christy, Am. Miner., 2007, in press. 